\title{
Current Concepts in Therapy of Chronic Rhinosinusitis and Nasal Polyposis
}

\author{
Jan Gosepath Wolf J. Mann \\ Department of Otolaryngology, Head and Neck Surgery, School of Medicine, University of Mainz, Mainz, Germany
}

\section{Key Words}

Chronic rhinosinusitis · Nasal polyps · Aspirin

sensitivity Endonasal sinus surgery

\begin{abstract}
The exact pathophysiological mechanisms leading to chronic rhinosinusitis (CRS) still to a large extent remain obscure. However, recently there has been some progress in elucidating the etiology of nasal polyposis, especially regarding tissue eosinophilia as well as the role of aspirin intolerance and eicosanoid mediators. Endonasal sinus surgery has evolved to be the treatment of choice in CRS and nasal polyposis in all cases where conservative treatment has failed or resulted in only a partial or temporary relief. Today, state of the art in surgical technique includes the ability to combine microscopic and endoscopic procedures. Regardless of technical advances like powered instrumentation or computer-aided surgery, in a modern protocol, surgical therapy can offer only one option within a complex and individually tailored therapeutical concept. This review discusses current concepts and new developments in the diagnosis and treatment of CRS and nasal polyposis.

Copyright $\odot 2005$ S. Karger AG, Basel
\end{abstract}

\section{Definition and Epidemiology of Chronic Rhinosinusitis}

Chronic rhinosinusitis (CRS) is mostly referred to as a multifactorial disease, which has been variously defined by far. It seems justified to use the term rhinosinusitis, as rhinitis and sinusitis are very often a continuum of one disease [1]. The heterogeneity of the various definitions is based on the use of different criteria. One well-accepted definition of CRS, which includes patients with nasal polyposis, was proposed by the International Conference on Sinus Disease in 1993: Criteria for CRS were defined as persistent symptoms and signs for 8 weeks or four episodes per year of recurrent acute sinusitis, each lasting at least 10 days, in association with persistent changes on the computed tomographic scan, 4 weeks after medical treatment, without intervening acute infection [2]. Recently published data have proposed a common etiological pathway for all clinical variations of polypous CRS, describing a systemic immunological response to fungal organisms located in sinonasal mucus as a causative mechanism [3]. This hypothesis and its relevance with respect to the pathophysiology of CRS in general is subject to an ongoing controversial discussion.

\begin{tabular}{ll}
\hline KARGER & ( ) 2005 S. Karger AG, Basel \\
0301-1569/05/0673-0125\$22.00/0 \\
$\begin{array}{l}\text { Fax +4161306 12 34 } \\
\begin{array}{l}\text { E-Mail karger@karger.ch } \\
\text { www.karger.com }\end{array}\end{array}$ & $\begin{array}{l}\text { Accessible online at: } \\
\text { www.karger.com/orl }\end{array}$
\end{tabular}

Jan Gosepath, MD, PhD

Universitäts-HNO-Klinik

Langenbeckstrasse 1

DE-55101 Mainz (Germany)

Tel. +49 6131 177361, Fax +49 6131 176637, E-Mail gosepath@hno.klinik.uni-mainz.de 
Epidemiologically, CRS appears to be of increasing relevance. Kennedy [4] reported in 1994 that patient visits due to chronic sinusitis showed an increase of 8 million to a total of 24 million per year between 1989 and 1992. The prevalence of the disease was estimated at $14 \%$ of the overall population in the USA in a study published in 1997 [5] and it has become the most common chronic disease with approximately 37 million cases in the USA [6, 7]. It has also been described that CRS is positively correlated to particular diseases, for example, CRS is found in $25-30 \%$ of all allergic patients [8], in 37\% of patients with transplants and in 54-68\% of patients with AIDS [9]. Nasal polyps are present in $10-15 \%$ of asthmatic patients [10].

Several histological and immunohistochemical aspects are universally found in CRS and might play a prominent role in the pathophysiology of this disease.

\section{Nasal Polyposis and Tissue Eosinophilia}

Despite the heterogeneous entities that are possibly related to or associated with the etiology of polypous CRS, one aspect appears to be universal for all variations of the disease. The polypoid tissue of the inflamed sinonasal mucosa shows eosinophilia on histological examination in the vast majority of cases. Davidsson and Hellquist [11] reported eosinophilia in tissue specimens in $88 \%$ of cases. A study from our group showed an increase of eosinophilia in patients with inhalant allergies when compared to nonallergic patients. A comparable increase was seen in aspirin-intolerant patients. Interestingly, the highest levels of eosinophilia were found in patients suffering from both inhalant allergies and aspirin intolerance [12]. Functionally, eosinophilic granulocytes are known to carry a variety of cytotoxic proteins in their granula, which can be released by degranulation. These proteins include the eosinophilic cationic protein, major basic protein, eosinophilic peroxidase and eosinophil-derived neurotoxin (EDN). Eosinophilic Cationic Protein, for example, is known to be a reliable marker for inflammatory activity in various types of rhinitis. However, recently published data suggest that the cytotoxicity of the eosinophils may be a crucial element of an immunological reaction against fungi, which are present in the nasal mucus [3]. The proposed paradigm for a common etiology of all various types of CRS postulates that eosinophils leave the nasal tissue and migrate into the nasal mucus, where they degranulate and unload their toxic proteins, especially major basic protein onto fungal elements. This was shown morphologically by histological examination of the nasal mucus. Using hematoxylin-eosin staining, eosinophilic clusters were detectable in these specimens. Silver staining as well as a newly developed chitinase staining [13] unveiled the presence of fungal elements within these clusters. It was, furthermore, concluded that this eosinophilic, cytotoxic mucin would lead to secondary epithelial damage in the respiratory lining, promoting bacterial invasion as an explanation for the recurrent, acute bacterial infections in these patients. This theory was based on the observation that fungi are essentially present in $100 \%$ of cultures taken from the human nasal mucus. In this study, fungal cultures were positive in $98 \%$ of 202 patients and in $100 \%$ of 14 controls. A total of forty-one species were found, up to eight in one sample/patient. The most common were alternaria (48\%), penicillium (42\%), candida (28\%) and aspergillus (17\%). Ponikau et al. [3] concluded from these findings that the term chronic sinusitis should be replaced by eosinophilic fungal rhinosinusitis.

However, it appears unlikely that the postulated eosinophilic immune response to an extramucosal target is initiated without a mechanism processing the information and passing it on into the tissue. To examine whether or not fungal DNA is present in tissue specimens taken from patients undergoing microscopic endonasal surgery for nasal polyposis, we applied a highly sensitive two-step polymerase chain reaction. Fungal DNA was detected in all the examined polyp specimens by polymerase chain reaction analysis, but not in healthy controls [14]. These findings suggest an antigen-presenting mechanism, initiating an immune response to extramucosal fungi in patients with a yet unexplained sensitization of their immune system to this stimulus. The possible relevance of this finding in the etiology of polypous CRS needs to be discussed.

\section{Role of Eicosanoid Mediators and Growth Factors in} the Etiology of Nasal Polyps and Aspirin Intolerance

In vitro analysis of eicosanoid release from mixed leukocyte cultures using a functional enzyme immunoassay offers a new tool not only to help establish the diagnosis of aspirin intolerance, but also to individually monitor the effect and verify the success of a desensitization therapy over time [15-17]. Long-term follow-up over at least 3 years in a large group of patients undergoing desensitization using a maintenance dose of as little as $100 \mathrm{mg}$ of aspirin a day revealed to be effective both clinically as well as in vitro. Eicosanoid levels shifted back to a normal release during therapy with an increase of the cyclooxy- 
genase $(\mathrm{COX})$ release in relation to the leukotriene release. This underlines a prominent role of COX mediators, which is in keeping with findings in recurrent nasal polyposis of aspirin-tolerant patients. Immunohistochemical staining of polypoid tissue revealed a downregulation of COX isoenzyme-2 (COX-2) in these tissues as compared to normal nasal mucosa [18]. This unveils a possible mechanism of the increased proinflammatory leukotriene release in nasal polyps, since COX-mediated prostaglandin E2 inhibits leukotriene release in nasal mucosa of normal controls.

Until today, the exact etiological mechanisms leading to the formation of nasal polyps remain obscure. However, this entity of chronic inflammatory disease of nasal respiratory mucosa is associated with remarkable edema. Vascular permeability/vascular endothelial growth factor (VPF/VEGF) plays an important role in inducing angiogenesis and/or modulating capillary permeability. We investigated the expression and localization of VPF/VEGF in nasal polyps as compared to healthy controls in order to evaluate its significance in the pathophysiology of nasal polyps. The expression of VPF/VEGF in specimens of nasal polyps was markedly stronger than in specimens of healthy nasal mucosa of controls [unpubl. data]. VPF/ VEGF labeling in polypous tissue was located in vascular endothelial cells as well as in basilar membranes and epithelial cells. The observed expression pattern in nasal polyps as opposed to controls of healthy nasal mucosa suggests that VPF/VEGF might play a significant role in the etiology of nasal polyposis. These findings need to be discussed with respect to the differential expression of COX1 and -2 in nasal polyps, where COX-1 is up- and COX-2 is downregulated, following immunohistochemical analysis [18]. Studies involving intestinal hyperplastic polyps suggest that especially COX-1 can upregulate VPF/VEGF [19-21]. This mechanism might play a key role in polyp growth and heavy edema formation in nasal polyposis.

\section{Therapeutical Concepts}

The challenge of treating CRS today is to offer patients a therapeutical concept that includes individually relevant etiological factors, but is based on well-standardized and validated pathways of medical and/or surgical therapy. In the first ever prospective, randomized placebo-controlled trial Richstein and Mann [22] were able to show that patients with CRS respond positively to phytotherapeutic treatment. The gold standard of treatment for CRS and nasal polyposis today, however, still is surgical thera- py, often in combination with topical and systemic medical treatment. Regardless of the surgical technique applied, a fair amount of patients, especially with polypoid changes, will at some point in time present with recurrent disease. Given the numerous factors involved, there are basically three problems responsible for the recurrence rate found in these patients: (1) technically unavoidable recurrences, (2) inadequate previous surgery and (3) incomplete etiological exploration.

\section{Diagnostic Exploration}

Exploration of patients suffering from CRS is rather complex. It is crucial to evaluate the relevance of several possible etiological factors and pinpoint those that play a role in the individual pathogenetic constellation of a given patient. A complete workup should include the following aspects: inhalant allergies, ciliary dysfunction, aspirin intolerance, immunodeficiency, the presence of fungal antigens and/or an immunological reaction to fungi as well as the presence of bacteria resistant to the applied antibiotic treatment.

Testing for inhalant allergies includes prick-, intracutaneous and RAST-testing followed by nasal provocation testing, if clinically indicated. Dysfunction of mucociliary clearance can be detected using a simple diagnostic tool. This is the clinical test of saccharin transport time (STT), where a piece of saccharin is placed on the head of the inferior turbinate and time is measured until a clear sweet sensation is felt in the pharynx. Physiologically a sweet sensation will be noticed after between 8 and $20 \mathrm{~min}$. The functional integrity of the ciliary cells as motor units can be identified with the help of video interference contrast microscopy. This is a very valuable method to rule out syndromes of primary ciliary dyskinesia. Any impairment of mucociliary transport can be clinically relevant, as persistent stasis of the mucus blanket will trigger recurrent rhinosinusitis. In a study published in 1997, we showed that patients suffering from recurrent CRS often do have a prolonged STT, but rarely a significant decrease in ciliary activity [23]. These observations could be explained either by the poor co-ordination of ciliary activity in these patients and/or alterations of the nasal mucus in terms of viscosity and its content of enzymes and/or inflammatory mediators. However, this study was able to show that endonasal sinus surgery may improve mucociliary transport time, measured by STT, in severe CRS.

\section{Diagnosis of Aspirin Intolerance}

One very critical group in the range of patients suffering from nasal polyposis is that of individuals with aspirin 
intolerance. It is known that this particular patient group has a very high risk of recurrence of sinonasal polyposis independent of the number and kind of previous surgical interventions. The diagnosis of aspirin intolerance (AI) is not always associated with the full clinical picture of the aspirin triad, which consists of: (1) nasal polyposis, (2) intrinsic bronchial asthma, and (3) aspirin-induced worsening of asthmatic symptoms, often along with nasoocular symptoms [24]. However, in sensitive individuals, even very small single doses of aspirin may cause rhinorrhea, bronchiolar constriction and shock symptoms related to a non-IgE-mediated pharmacological hypersensitivity reaction [25]. Not only aspirin, but also most other NSAIDs interact with the eicosanoid pathway. They are known to cause inhibition of the COX, which metabolize arachidonic acid to prostaglandins. This inhibition leads to an upregulation of the alternative pathway with lipoxygenases metabolizing arachidonic acid to leukotrienes. An in vitro assay can be very valuable in establishing the diagnosis of aspirin intolerance [15]. The alteration of arachidonic acid metabolism and eicosanoid release can as well be detected in patients with an incomplete manifestation where the clinical picture of the aspirin triad has not yet fully developed. This assay has been successfully used at our institution, following a recently published protocol [26]. Considering the role of COX in the inflammatory process in nasal polyps, our own data from recent histochemical studies indicate that both isoforms, COX 1 and COX 2, are mostly located in structures of the respiratory epithelial lining and also to a large extent in glandular structures [18]. The examined specimens were taken from patients with nasal polyposis. This observation might give an important insight into the histopathology of the inflammatory disease as it indicates which structures are mainly involved in prostaglandin production within polypoid tissue. However, it is not yet known whether prostaglandin production in glandular structures might indicate a secretion of these molecules into the nasal mucus.

\section{Role of Conservative/Medical Treatment}

Taking all the above-mentioned aspects into consideration, certain applications of medical treatment should have a prominent role in the treatment of CRS and can be valuable in reducing the risk of recurrent nasal polyposis and especially in patients who previously underwent one or multiple surgical interventions. This has been proven very early for specific phytotherapeutic regimes [22]. In CRS, patients may show an improvement in subjective symptoms to an extent of approximately $25 \%$ in so-called 'stable episodes' over a 4-week period, whereas objective clinical parameters vary insignificantly. mRNA of IL-1 $\beta$, IL-6, IL-8, MCP-1 and TNF- $\alpha$ as well as pLT and PGE 2 levels are detectable and appear to play a role in the persistence of inflammation in CRS. Their level decreases only insignificantly over time, even in the absence of acute exacerbation of disease, rendering the mucosa possibly more prone for recurrent acute episodes [27].

\section{Steroids}

Steroids, used topically or systemically or both generally have a strong anti-inflammatory effect and can reduce eosinophilia as they directly interact with several chemokines and cytokines involved in the inflammatory process. Especially the suppressive effect on the T-cell production of IL-5 is an important aspect in this regard [28, 29]. A large number of symptomatic clinical reports as well as prospective studies involving objective measurement of nasal function have established the role of topical steroids in polypoid CRS [30-39]. The main indication seems to be in the postoperative period, where they seem to have beneficial effects on the rate and frequency of relapsing polyps $[40,41]$. Systemic corticosteroids have been evaluated in nasal polyposis and seem to go along with temporary symptomatic relief and can help to delay or facilitate surgical interventions [42-45].

\section{Aspirin Desensitization}

All patients who are diagnosed with aspirin intolerance have a considerable chance of improvement or decreased risk of recurrence, if adaptive desensitization therapy is performed. In a prospective study, we were able to show the effectiveness of a new protocol using a maintenance dose of only $100 \mathrm{mg}$ of oral aspirin a day [17]. To initiate the desensitization therapy, oral aspirin was given in increasing dosages over 2 days [day 1: $100 \mathrm{mg}$ (two doses of $50 \mathrm{mg}$ ), day 2: $500 \mathrm{mg}$. Patients were hospitalized for these initial 2 days. Airway resistance and FEV1 were closely monitored during this induction period. On the first day after an initial lung function test, $50 \mathrm{mg}$ was given in the morning and only after a repeated check of airway resistance and FEV1 the second $50 \mathrm{mg}$ was administered orally, usually $8 \mathrm{~h}$ after the initial dose. On the second day, $500 \mathrm{mg}$ was given orally if repeated lung function test had not revealed a decrease in FEV1 of $25 \%$ or greater. On the third day, aspirin was reduced to the daily dose of only $100 \mathrm{mg}$ to be kept as a long-term maintenance 
dose. Clinical reassessment as well as the functional in vitro assay were repeated at each follow-up visit of every patient in an attempt to identify changes in the release of eicosanoids over time and to correlate these with the clinical course. Since there is a relative overproduction of $\mathrm{pLT}$ in aspirin-sensitive individuals, it is desirable to achieve an increase of the 'PGE2/pLT index' over time. We observed a significant improvement of in vitro findings, which was positively correlated to the individual clinical course and the recurrence rate of nasal polyps observed in this group of patients $[16,17]$.

The data underline the role of the in vitro assay and indicate the effectiveness of a desensitization protocol, that can be maintained as a long-term treatment without adverse side effects. Results suggest that the recurrence rate of nasal polyps after surgical therapy can be reduced using this protocol, however, only long-term treatment can secure a beneficial outcome over time.

\section{Topical Antifungal, Antiseptic or Antibiotic Treatment}

First, controlled clinical studies, which are currently conducted, will define the role of a topical antifungal treatment, using nasal washes with amphotericin B, after initial reports have indicated promising results [46]. However, the long-term efficacy of topical solutions in CRS has not been demonstrated.

In a recently published prospective study, we evaluated effects of different concentrations of several topical solutions on mucociliary clearance, measured by ciliary beat frequency (CBF) over time [47]. In controls, perfused with cell culture medium (RPMI) only, CBF was measured at an average of $9.5 \mathrm{~Hz}( \pm 1.7 \mathrm{~Hz})$, which remained constant over more than $12 \mathrm{~h}$. Perfusion with a $5 \%$ solution of ofloxacin as an antibiotic solution led to an average CBF of $8 \mathrm{~Hz}$, but the ciliary activity ceased after $7 \mathrm{~h}$. With a $50 \%$ ofloxacin solution, average CBF was only $7.5 \mathrm{~Hz}$ and stopped after $6 \mathrm{~h}$ and $30 \mathrm{~min}$. Using antiseptic solutions, perfusion with $5 \%$ of betadine revealed an average CBF of $7 \mathrm{~Hz}$, which was kept up for $1 \mathrm{~h}$ and $30 \mathrm{~min}$, however, with $10 \%$ it was down to $4.5 \mathrm{~Hz}$ and lasted for only $30 \mathrm{~min}$. Hydrogen peroxide was used in a $1 \%$ and in a $3 \%$ solution and seemed less ciliotoxic than betadine as $1 \%$ led to an average $\mathrm{CBF}$ of $7 \mathrm{~Hz}$, which was kept up for over $8 \mathrm{~h}$ and $3 \%$ to $6 \mathrm{~Hz}$ for $5 \mathrm{~h}$ and $30 \mathrm{~min}$. Using antifungal solutions, amphotericin B revealed only little ciliotoxicity in low concentrations, as $\mathrm{CBF}$ was measured at $9 \mathrm{~Hz}$ for $8 \mathrm{~h}$ at a concentration of $2.5 \%$ and at $8 \mathrm{~Hz}$ for $7 \mathrm{~h}$ at $5 \%$.
After increasing the concentration to a $10 \%$ solution, CBF dropped to $3.5 \mathrm{~Hz}$ and lasted only $2 \mathrm{~h}$. Interestingly, there was no dose-dependent effect to be observed after perfusion with clotrimazole at all three chosen concentrations of 10, 20 and 50\%. CBF remained at a constant average frequency of $9 \mathrm{~Hz}$, but $\mathrm{CBF}$ stopped after no more than $30 \mathrm{~min}$ in all experiments. The strongest dose dependence was seen for itraconazole: at a concentration of $25 \%$ a CBF of $6 \mathrm{~Hz}$ lasted for $7 \mathrm{~h}$ and $45 \mathrm{~min}$, at $5 \%$ the ciliary activity went down to $1 \mathrm{~h}$ and $15 \mathrm{~min}$ at $6 \mathrm{~Hz}$ and at $1 \%$ it was only $3 \mathrm{~Hz}$ for $30 \mathrm{~min}$.

\section{Systemic Antibiotics and Antihistamines}

Antibiotic treatment has not been established as an effective treatment in patients with CRS. A prominent pathogenic role of bacteria seems to be limited to acute forms of rhinosinusitis and is doubtful in CRS [48, 49]. Thus, antibiotic treatment has only been proven effective in acute sinusitis [50-52]. There are only limited data from controlled studies on antibiotic treatment in CRS; however, a long-term effect on the course of CRS has never been shown [53-57].

Antihistamines are known to play a role in the adjuvant treatment of sinusitis, but no efficacy has been established for antihistamines in CRS without allergic rhinitis being present as an underlying condition $[58,59]$.

\section{Surgical Treatment}

Surgery is the treatment of choice in CRS in the presence of massive panpolyposis and/or when efforts of conservative treatment after individual etiological evaluation have failed or only gone along with partial or temporary relief. In such situations endonasal sinus surgery is the gold standard of therapy as a relative indication [60]. There are absolute indications for surgical interventions such as orbital, endocranial and septic complications [6163]. Any suspicion of malignancy is also an absolute indication for surgery [64]. Thorough preoperative workup including endoscopy and modern imaging techniques as well as the application of advanced microscopic and/or endoscopic surgical techniques have resulted in an increased number of both benign and malignant tumorous lesions that can today be removed endonasally. Such endonasal tumor removal in centrally located neoplasms without far lateral or cranial extensions has revealed encouraging results and is associated with limited surgical 
trauma, reduced morbidity and accelerated postoperative recovery for this group of patients [65].

In a chronic inflammatory disease like CRS the main goal of any surgical intervention - just like in any form of conservative treatment - is to restore ventilation and drainage of the involved paranasal sinuses and recreate an effective mucociliary clearance.

\section{Endonasal Sinus Surgery}

The classical approaches to the surgical treatment of the paranasal sinuses such as the Caldwell-Luc technique were most commonly used until the 1970s, when endoscopy was first applied to the nose and the paranasal sinuses and endonasal surgical techniques became available. After Messerklinger [66, 67] had first promoted the use of the endoscope, the advantages of this endonasal optical control were promoted by different authors around the world [60-70]. The striking difference in the surgical management of CRS with the endonasal techniques was the ability to be much more conservative with regard to the mucosal linings as opposed to the classical technique. The term functional endoscopic sinus surgery (FESS) was and is still used to describe this less radical approach [69, 71]. This terminology implies that under direct visualization only affected mucosa is removed, just enough to restore ventilation and drainage according to the individual pathology. Surgery can thus be tailored to the severity of the individual condition in an effort to minimize trauma and accelerate wound healing [69, 71].

Kennedy [72] published a very detailed analysis of prognostic factors, outcomes and staging in ethmoid sinus surgery in 1992 . Over 240 data fields were collected from each of the 120 patients who underwent endoscopic sinus surgery. The exact extent of the disease revealed to be the only relevant prognostic factor. A strong correlation was identified between the extent of disease and the surgical outcome while all other potential factors seemed to have little or no relevance. Kennedy [72], therefore, suggested a staging system for inflammatory sinus disease based on the individual extent of the disease. Such staging systems were then elaborated and applied by different authors in slight variations [72-75].

\section{Efficacy of the Endonasal Technique}

Different authors have evaluated the efficacy of endonasal sinus surgery.

Lund et al. [76-78] published data obtained by an objective assessment of FESS in the management of CRS.
The authors had used visual analog scoring for subjective symptoms, measurement of $\mathrm{CBF}$, qualitative olfactometry and anterior rhinomanometry in a prospective series of 24 patients who underwent endoscopic sinus surgery for CRS [77]. All subjective symptoms examined as well as CBF showed significant improvement while quantitative olfaction testing and rhinomanometry did not improve in a significant manner. This study offered quantitative evidence of clinical improvement after this endoscopically performed surgery, supporting the pathophysiological concepts on which this technique is based.

Stammberger [70, 79, 80] described and evaluated functional endoscopic treatment, following Messerklinger's ideas, in a series of publications. He detailed the underlying anatomic and pathophysiological considerations as well as the surgical techniques. He emphasized in these reports that a functional intervention as opposed to a radical one was justified due to the key role of the anterior ethmoid and its infundibulum for infection and cure in CRS. He concluded from years of endoscopical investigation and observation that both the maxillary and the frontal sinuses are dependent on pathophysiological conditions in this area [79]. His surgical experience was in support of this paradigm, as results using a functional endoscopic approach to the ethmoid turned out to have the same postoperative results as the classic Caldwell-Luc operation [70].

Stammberger et al. [81] evaluated the FESS technique versus the Caldwell-Luc approach in a trial involving 50 patients with recurrent CRS after previous surgical intervention. He concluded that the key advantage of the endonasal technique was that it would aim at the primary infective foci within the anterior ethmoid and would usually cure disease in the larger dependent sinuses without addressing the latter surgically.

McCaffrey [82] described FESS as a minimally invasive technique for the treatment of chronic and acute sinusitis in keeping of the above-mentioned pathophysiological concept. This review also concluded that the need for radical approaches to the ethmoid region and the Caldwell-Luc operations had decreased.

In a prospective and retrospective review of 200 patients, Smith and Brindley [83] found in 1993 that $88 \%$ of all patients were symptom free or improved after FESS. However, $41.5 \%$ of the patients in this study did still require some medical therapy after a mean follow-up of 17 months.

A prospective, randomized multicenter analysis by Kuehnemund et al. [84] recently compared results of endonasal sinus surgery, performed by an extended versus 
a limited approach. Limited approach was defined as a minimally invasive procedure focused on the anterior ethmoid and its infundibulum, while an extended approach included surgical opening of all dependent sinuses or an endonasal pansinus operation. Patients were assessed preoperatively as well as 3 and 6 months postoperatively by clinical symptoms, examination including endoscopy and measurement of STT. Analysis of the results revealed that surgical results as well as the severity of subjective symptoms were similar in both groups of patients, suggesting that the conservative approach is sufficient to effectively address the symptomatology associated with CRS.

\section{Microscopic Technique}

In further development of the endonasal techniques, the surgical microscope was also applied with the advantages of stereoscopic vision and the possibility for the surgeon to work bimanually. This allows for simultaneous suctioning throughout the procedure, which is associated with improved visualization of the surgical field and reduced surgical time [85-88]. One potential drawback of the microscopic versus the endoscopical approach is the limitation to a straight line of vision as opposed to the option of using angled endoscopes, for example, to visualize pathologies within the frontal or maxillary sinuses. Today, state of the art in surgical technique includes the ability to combine microscopic and endoscopic procedures in one operation. Whether a surgeon prefers one or the other as a standard technique certainly is related to personal experience using either of them; however, the combination of both appears to be advantageous especially in difficult revision cases.

There have been efforts to combine the advantages of both in one optical device; however, such devices have not yet been established in a routine setting [89].

\section{Powered Instrumentation}

In the second half of the 1990s initial publications reported the use of a microdebider, similar to shavers used in orthopedic and temporomandibular joint surgery, in endonasal sinus surgery [90-99]. This technique was and is still used by a number of sinus surgeons and holds advantages as well as drawbacks. In contrast to the classical endoscopic sinus surgery, it offers - just like the use of the microscope - improved visualization due to simultaneous and continuous suctioning. This is associated with the saving of surgical time, especially in revisions and/or in the presence of massive edematous polyposis within the nasal cavity. However, in the hands of an inexperienced surgeon, the use of such instruments is also certainly accompanied with an increased risk of unintended injury of important or vital structures like lamina papyracea, intraocular muscles and/or base of skull [97]. There have been several efforts to quantitatively and qualitatively evaluate the pros and cons of powered instrumentation in endonasal surgery [97-99]. Kuhnel et al. [97] stated in their analysis of the feasibility and the benefits of this technique that it was particularly helpful in revision cases of CRS in an outpatient setting. They confirmed dangers and limitations like the ineffectiveness of these instruments in the reduction of stronger bony structures. However, they concluded that shaves offered significant advantages in soft tissue manipulations, especially in revisional outpatient surgery for recurrent sinusitis. In a prospective randomized trial, however, we were not able to show a beneficial effect of microdebriders on surgical outcome after 3 months, 6 months and in the long-term compared to conventional instruments [100].

The use of microdebriders in paranasal sinus surgery certainly should be limited to the hands of an experienced surgeon. Then these devices can be seen as an helpful technique allowing for precise and minimally invasive endonasal sinus surgery.

\section{Computer-Aided Surgery (CAS)}

Especially in the treatment of the frontal sinuses, recurrences sometimes appear to be technically unavoidable as they might be related to persistent inflammatory processes and quick recurrence of polyps, scar tissue formation and/or the formation of mucoceles. In order to minimize surgical time as well as intraoperative anatomical/ topographical uncertainties due to the presence of scaring and hyperostosis or the absence of anatomical landmarks after previous interventions, computer-aided navigational devices have been established and proven to be potentially helpful in endonasal surgery.

After the technological basis for such systems had rapidly developed in terms of the necessary hard- and software, several centers reported an increased efficacy and applicability of the devices in endonasal and skull base surgery [101-111]. Till today, the main goal of computeraided surgery (CAS)-manufacturers is to increase the precision and enhance the practicability to a point where a routine application would be easy and reliable [105108]. 
Ecke et al. [107] investigated hard- and software errors as well as errors of image acquisition and transfer, of patient registration and of user-related and strategic errors in 436 applications of CAS in sinus surgery. Khan et al. [108] reported experiences with a first optoelectrical system, which was used in 60 cases of endonasal surgery in patients with CRS. The main advantage of this system as opposed to electromagnetical ones is the possibility to use standard instruments without causing distortion, whereas electromagnetical navigational devices require nonmagnetic instruments, leading to additional costs. The accuracy of either of these systems today is high and shifting is limited to between 0.5 and $2.0 \mathrm{~mm}$ [109-111].

Today CAS can support and expedite difficult revision cases of endonasal sinus surgery, especially in the absence of anatomical landmarks, but it should be handled by experienced hands who will immediately recognize a possible malfunction and/or a lack of accuracy. In an academic setting, there is a role for such devices as teaching tools, which can be helpful in creating a topographic and three-dimensional understanding of the respective surgical procedure [105-107].

\section{Risks and Complications of Endonasal Sinus Surgery}

Several groups have published their experiences regarding minor and major complications of endonasal sinus surgery [112-117]. Following a survey in Great Britain, the overall rate of complications was $0.69 \%$. Major complications occurred in $0.25 \%$ and minor complications in $0.44 \%$. The following are regarded as the most frequent complications of endonasal sinus surgery: periorbital injury, orbital lesions, dural injury, endocranial lesions and damage to the internal carotid artery. Major complications are generally fatality, bleedings of the internal carotid artery and those that cause persistent damage to the patient like persistent neurological deficits or permanent loss of vision $[118,119]$. Interestingly, the incidence of such events does not seem to depend on the experience of the respective surgeon $[118,119]$, neither did it drop after the introduction of navigational devices and CAS [119]. In an analysis of the first 300 consecutive interventions of six surgeons ( 1,800 surgical cases), Weber et al. [118] did not observe a single major complication, but only periorbital lesions $(\mathrm{n}=33)$ or cerebrospinal fluid leaks, which could easily be repaired $(n=8)$. The authors also analyzed 16 malpractice cases related to endonasal operations and found that 9 of these were attributable to experienced surgeons, 5 to moderately experienced surgeons and only 2 to inexperienced surgeons. There seems to be evidence that the inexperienced surgeon is more prone to create cerebrospinal fluid leaks while a more experienced surgeon would rather have a tendency toward involuntary laceration of the periorbit. Generally the likelihood of encountering a complication is correlated with the absence of normal anatomical landmarks, anatomical variations, the amount of intraoperative bleeding as well as the duration of the patients' medical history related to symptoms of CRS [120].

These data show that any surgeon performing endonasal sinus surgery needs to be willing to exercise repeated self-criticism and needs to be constantly alert to the possible anatomical variations and the specific pathological findings in each individual case in an effort to minimize the rate of complications $[114,116,118,119]$.

\section{Evaluation of Endonasal Sinus Surgery Regarding Nasal Physiology, Nasal Symptoms, Olfaction and Quality of Life}

Several investigators have used objective data for the evaluation of success in endonasal surgery. Hafner et al. [23] reported that mucociliary transport is significantly improved after endonasal sinus surgery in patients with severe CRS. In this same investigation, the authors found that those patients who continued to have a prolonged mucociliary transport time as measured by STT had a high risk of developing recurrent disease. These data are indicating that STT is a reliable marker to objectively assess the functional status of sinonasal mucosa as an indication of the functional benefit of endonasal sinus surgery.

In a different investigation, we evaluated another objective parameter, acoustic rhinometry, with respect to its predictive value in terms of outcomes after sinonasal surgery [121]. In this prospective study, patients were evaluated using acoustic rhinometry pre- and postoperatively and results were correlated with a semiquantitative sinonasal outcome survey. Results indicated that patients with a rhinometrically wider geometry at the plane of the head of the inferior turbinate were significantly more likely to report a subjective improvement postoperatively than patients with a narrower geometric situation at this plane of the nasal cavity. These findings also underline the relevance of objective nasal assessment in the evaluation of endoscopic endonasal surgical outcomes. 
Abdel-Hak et al. [122] prospectively investigated CBF and changes in olfaction pre- and postoperatively up to 6 months in 70 patients who underwent FESS for CRS. They observed statistically significant improvement in both CBF as well as subjective and objective olfactory function.

The positive effects of endonasal sinus surgery on olfaction were confirmed by other studies. In another prospective trial, Klimek et al. [123] measured olfactory threshold, odor identification and odor discrimination ability of patients with nasal polyposis after endonasal surgery. Their results demonstrated that olfactory function is impaired in patients with nasal polyps and that endonasal sinus surgery might improve the ability of both odor identification and discrimination. The results were best at 3 months after surgery and showed a tendency to poorer olfactory function in further course of time. Delank et al. [124] found similar results but warned that the resection of the middle turbinate during endonasal surgery might have a negative effect on olfaction due to possible damage to olfactory filia and alterations of the physiological aerodynamic pattern within the olfactory cleft. Rowe-Jones and Mackay [125] performed subjective and objective olfaction testing in a prospective study of 115 patients before and 6 weeks after endoscopic sinus surgery. These data were correlated with the change in volume of the nasal cavity as measured by acoustic rhinometry. Results showed that the improvement in all olfactory symptom scores correlated in a significant manner with the increase of nasal volume.

There are also reports about positive long-term effects of management of CRS and nasal polyposis by endoscopic sinus surgery on bronchial asthma. Dunlop et al. [126] stated that in these patients aggressive management of sinonasal pathology could improve asthma status after an analysis in 50 asthmatic patients with a follow-up of 12 months. Senior et al. [127] followed 120 patients with CRS and asthma over an average of 6.5 years. They confirmed that a combination of FESS, careful postoperative care and appropriate medical therapy for CRS has a favorable long-term effect on bronchial asthma in these patients.

Given the very high and still increasing worldwide prevalence of CRS, the effects of the disease and of any therapeutical effort on the patient's subjective quality of life are of broad interest and need to be extensively evaluated [128, 129]. Damm et al. [130] evaluated the impact of FESS on symptoms and the quality of life in CRS in 279 patients who completed questionnaires that assessed subjective symptoms and complaints using ranking scales. This investigation concluded that the restriction of quality of life in patients with CRS is mainly caused by an airway obstruction and a postnasal drip. These symptoms were excellently improved by the performed FESS procedures in the majority of these patients, thereby achieving a better quality of life in the long term.

\section{Conclusion}

Many pathophysiological factors of CRS have been identified, but a lot of questions, especially in the etiology of nasal polyposis, still remain unanswered. However, in all instances where conservative therapeutical efforts fail, endonasal sinus surgery, since the advent of endoscopic and microscopic surgical techniques, has evolved to be the gold standard of treatment. Many investigations seem to prove the efficacy of a rather limited, minimally invasive approach as opposed to a radical procedure. Longterm benefit in terms of nasal symptoms and the quality of life has been confirmed by numerous studies. However, due to the high risk of recurrence of disease in patients suffering from polypous CRS, surgical treatment can only serve as one important aspect of a rather complex therapeutical concept. This concept needs to be individually tailored with respect to the heterogeneous aspects of the etiology of the disease in this particular group of patients. 


\section{References}

1 Gwaltney JM, Philipps CD, Miller RD, et al: Computed tomography study of the common cold. N Engl J Med 1994;330:25-30.

$\checkmark 2$ Lund VJ, Kennedy DW: Quantification for staging sinusitis. The staging and therapy group. Ann Otol Rhinol Laryngol Suppl 1995; 167:17-21.

-3 Ponikau JU, Sherris DA, Kern EB, Homburger HA, Frigas E, Gaffey TA, Roberts GD: The diagnosis and incidence of allergic fungal sinusitis. Mayo Clin Proc 1999;74:877-884.

4 Kennedy DW: Sinus diseases: Guide to first line management. Deerbach Beach, Health Commun, 1994,p 12.

$\checkmark 5$ Kaliner MA, Osguthrope JD, Fireman P, et al: Sinusitis: Bench to bedside. Current findings, future directions. J Allergy Clin Immunol 1997;99:829-848.

6 National Center of Health Statistics. Vital Health Stat 1995;10:199.

7 National Center of Health Statistics. Vital Health Stat 1994;10:190.

$>8$ Savolainen S: Allergy in patients with acute maxillary sinusitis. Allergy 1989;44:116-122.

$>9$ Porter JP, Patel AA, Dewey CM, et al: Prevalence of sinonasal symptoms in patients with HIV infection. Am J Rhinol 1999;13:203-208.

10 Batra PS, Kern RC, Tripathi, et al: Outcome analysis of endoscopic sinus surgery in patients with nasal polyps and asthma. Laryngoscope 2003;113:1703-1706.

11 Davidsson A, Hellquist HB: The so-called 'allergic' nasal polyp. ORL J Otorhinolaryngol Relat Spec 1993;55:30-35.

12 Kaldenbach T, Schafer D, Gosepath J, Bittinger F, Klimek L, Mann WJ: Significance of eosinophilic granulocytes in relation to allergy and aspirin intolerance in patients with sinusitis polyposa. Laryngorhinootologie 1999;78: 429-434.

$\checkmark 13$ Taylor MJ, Ponikau JU, Sherris DA, Kern EB, Gaffey TA, Kephart G, Kita H: Detection of fungal organisms in eosinophilic mucin using a fluorescin-labeled chitin-specific binding protein. Otolaryngol Head Neck Surg 2002;127: 377-383.

14 Gosepath J, Brieger J, Vlachtsis K, Mann WJ: Fungal DNA is present in tissue specimens of patients with chronic rhinosinusitis. Am J Rhinol 2003; in press.

15 Gosepath J, Hoffmann F, Schafer D, Amedee RG, Mann WJ: Aspirin intolerance in patients with chronic sinusitis. ORL J Otorhinolaryngol Relat Spec 1999;61:146-150.

-16 Gosepath J, Schaefer D, Amedee RG, Mann WJ: Individual monitoring of aspirin desensitization. Arch Otolaryngol Head Neck Surg 2001;127:316-321.

17 Gosepath J, Schafer D, Mann WJ: Aspirin sensitivity: Long term follow up after up to 3 years of adaptive desensitization using a maintenance dose of $100 \mathrm{mg}$ of aspirin a day. Laryngorhinootologie 2002;81:732-738
18 Gosepath J, Brieger J, Gletsou E, Mann WJ: Expression and localization of cyclooxygenases (Cox-1 and Cox-2) in nasal respiratory mucosa. Does Cox-2 play a key role in the immunology of nasal polyps? J Investig Allergol Clin Immunol 2003; in press.

19 Seno H, Oshima M, Ishikawa TO, Oshima H, Takaku K, Chiba T, Narumiya S, Taketo MM: Cyclooxygenase-2 and prostaglandin E (2) receptor EP (2) - Dependent angiogenesis in APC (Delta 716) mouse intestinal polyps. Cancer Res 2002;62:506-511.

20 Tsujii M, Kawano S, Tsuji S, Sawaoka H, Hori M, DuBois RN: Cyclooxygenase regulates angiogenesis induced by colon cancer cells. Cell 1996;87:803-809.

21 Kawada M, Seno H, Wada M, Suzuki K, Kanda N, Kayahara T, Fukui H, Sawada M, Kajiyama T, Sakai M, Chiba T: Cyclooxygenase-2 expression and angiogenesis in gastric hyperplastic polyp - Association with polyp size. Digestion 2003;67:20-24.

22 Richstein A, Mann WJ: Zur Behandlung der chronischen Sinusitis mit Sinupret. Ther Ggw 1980;119:3-7.

23 Hafner B, Davris S, Riechelmann H, Mann WJ, Amedee RG: Endonasal sinus surgery improves mucociliary transport in severe chronic sinusitis. Am J Rhinol 1997;11:271-274.

24 Samter M, Zeitz HJ: The aspirin triad and the protaglandins; in Samter M (ed): Immunological Diseases, ed 3, vol II. Boston, Brown, 1978, pp 900-927.

25 Szczeklik A, Gryglewski RJ, Czerniawskamysi G: Relation of inhibition of prostaglandin biosynthesis by analgesics to asthma attacks in aspirin sensitive patients. BMJ 1975;1:67-69.

26 Schaefer D, Schmid M, Goede U, et al: Dynamics of eicosanoids in peripheral blood cells during bronchial provocation in aspirin intolerant asthmatics. Eur Resp J 1999;13:638646.

27 Kühnemund M, Ismail C, Brieger J, Schaefer D, Mann WJ: Untreated chronic sinusitis, a comparison of symptoms and mediator profiles. Submitted for publication. Laryngoscope 2004; 114:528-532.

28 Bachert C, Geveart P: Effect of intranasal corticosteroids on release of cytokines and inflammatory mediators. Allergy 1999;54:116-123.

29 Rudack C, Bachert C, Stoll W: Effect of prednisolone on cytokine synthesis in nasal polyps. J Interferon Cytokine Res 1999;19:10311035.

30 Deuschl H, Drettner B: Nasal polyps treated by beclomethasone nasal aerosol. Rhinology 1977; 15:17-23.

31 Mygind N, Pedersen CB, Prytz S, Sorensen H: Treatment of nasal polyps with intranasal beclomethasone dipropionate aerosol. Clin Allergy 1975;5:159-164.

32 Filiaci F, Passali D, Puxeddu R, Schrewelius C: A randomized controlled trial showing efficacy of once daily intranasal budesonide in nasal polyposis. Rhinology 2000;38:185-190.
33 Holmberg K, Juliusson S, Balder B, Smith DL, Richards DH, Karlsson G: Fluticasone propionate aqueous nasal spray in the treatment of nasal polyposis. Ann Allergy Asthma Immunol 1997;78:270-276.

34 Keith P, Nieminen J, Hollingworth K, Dolovich $\mathrm{J}$ : Efficacy and tolerability of fluticasone propionate nasal drops 400 microgram once daily compared with placebo for the treatment of bilateral polyposis in adults. Clin Exp Allergy 2000;30:1460-1468.

35 Lildholdt T, Rundcrantz H, Lindqvist N: Efficacy of topical corticosteroid powder for nasal polyps: A double-blind, placebo-controlled study of budesonide. Clin Otolaryngol 1995; 20:26-30.

36 Lund VJ, Flood J, Sykes AP, Richards DH: Effect of fluticasone in severe polyposis. Arch Otolaryngol Head Neck Surg 1998;124:513518.

37 Ruhno J, Andersson B, Denburg J, Anderson M, Hitch D, Lapp P, Vanzieleghem M, Dolovich J: A double-blind comparison of intranasal budesonide with placebo for nasal polyposis. J Allergy Clin Immunol 1990;86:946-953.

38 Tos M, Svendstrup F, Arndal H, Orntoft S Jakobsen J, Borum P, Schrewelius C, Larsen PL, Clement F, Barfoed C, Romeling F, Tvermosegaard T: Efficacy of an aqueous and a powder formulation of nasal budesonide compared in patients with nasal polyps. Am J Rhinol 1998;12:183-189.

39 Virolainen E, Puhakka H: The effect of intranasal beclomethasone dipropionate on the recurrence of nasal polyps after ethmoidectomy. Rhinology 1980;18:9-18.

40 Hartwig S, Linden M, Laurent C, Vargo AK, Lindqvist $\mathrm{N}$ : Budesonide nasal spray as prophylactic treatment after polypectomy (a double blind clinical trial). J Laryngol Otol 1988; 102:148-151.

41 Karlsson G, Rundcrantz H: A randomized trial of intranasal beclomethasone dipropionate after polypectomy. Rhinology 1982;20:144-148.

42 Bonfils P: Medical treatment of paranasal sinus polyposis: A prospective study in 181 patients. Ann Otolaryngol Chir Cervicofac 1998;115: 202-214.

43 Cassano P, Marini F, Indraccolo AS, Curatoli FP: Corticosteroid therapy in the prevention of recurrent post-surgical nasal polyposis. Acta Otorhinolaryngol Ital 1996;16:334-338.

44 Rasp G, Kramer MF, Ostertag P, Kastenbauer E: A new system for the classification of ethmoid polyposis. Effect of combined local and systemic steroid therapy. Laryngorhinootologie 2000;79:266-272.

45 van Camp C, Clement PA: Results of oral steroid treatment in nasal polyposis. Rhinology 1994;32:5-9.

46 Ponikau JU, Sherris DA, Kita H, Kern EB: Intranasal antifungal treatment in 51 patients with chronic rhinosinusitis. J Allergy Clin Immunol 2002;110:862-866. 
47 Gosepath J, Grebneva N, Mossikhin S, Mann WJ: Topical antibiotic, antifungal, and antiseptic solutions decrease ciliary activity in nasa respiratory cells. Am J Rhinol 2002;16:25-31.

48 Nadel DM, Lanza DC, Kennedy DW: Endoscopically guided cultures in chronic sinusitis. Am J Rhinol 1998;12:233-241.

-49 Nadel DM, Lanza DC, Kennedy DW: Endoscopically guided sinus cultures in normal subjects. Am J Rhinol 1999;13:87-90.

-50 Axelsson A, Jensen C, Melin O, Singer F, von Sydow C: Treatment of acute maxillary sinusitis. V. Amoxicillin azidocillin, phenylpropanolamine and pivampicillin. Acta Otolaryngol 1981;91:313-318

-51 Lindbaek M, Hjortdahl P, Johnsen UL: Randomised, double blind, placebo controlled trial of penicillin $\mathrm{V}$ and amoxycillin in treatment of acute sinus infections in adults. BMJ 1996;313: 325-329.

52 van Buchem FL, Knottnerus JA, Schrijnemaekers VJ, Peeters MF: Primary-care-based randomised placebo-controlled trial of antibiotic treatment in acute maxillary sinusitis. Lancet 1997;349:683-687.

53 Rachelefsky GS, Katz RM, Siegel SC: Chronic sinusitis in children with respiratory allergy: The role of antimicrobials. J Allergy Clin Immunol 1982;69:382-387.

54 Clement PA, de Gandt JB: A comparison of the efficacy, tolerability and safety of azithromycin and co-amoxiclav in the treatment of sinusitis in adults. J Int Med Res 1998;26:66-75.

$\checkmark 55$ Wald ER, Chiponis D, Ledesma-Medina J: Comparative effectiveness of amoxicillin and amoxicillin-clavulanate potassium in acute paranasal sinus infections in children: A double-blind, placebo-controlled trial. Pediatrics 1986;77:795-800.

-56 Dohlman AW, Hemstreet MP, Odrezin GT, Bartolucci AA: Subacute sinusitis: Are antimicrobials necessary? J Allergy Clin Immunol 1993;91:1015-1023.

57 Legent F, Bordure P, Beauvillain C, Berche P: A double-blind comparison of ciprofloxacin and amoxycillin/clavulanic acid in the treatment of chronic sinusitis. Chemotherapy 1994; 40(suppl 1):8-15.

58 Renvall U, Lindquist N: A double blind clinical study with Monydrin tablet in patients with non allergic chronic rhinitis. J Int Med Res 1974;7:235-292.

\$59 Braun JJ, Alabert JP, Michel FB, Quiniou M, Rat C, Cougnard J, Czarlewski W, Bousquet J: Adjunct effect of loratadine in the treatment of acute sinusitis in patients with allergic rhinitis. Allergy 1997;52:650-655.

60 Smith LF, Brindley PC: Indications, evaluation, complications, and results of functional endoscopic sinus surgery in 200 patients. Otolaryngol Head Neck Surg 1993;108:688-696.

61 Eufinger H, Machtens E: Purulent pansinusitis, orbital cellulitis and rhinogenic intracranial complications. J Craniomaxillofac Surg 2001; 29:111-117.

Current Concepts in Therapy of Chronic

Rhinosinusitis and Nasal Polyposis
62 Marianowski R, Forcioloi J, Bouhnik M, Ait Amer JL, Brunelle F, Manach Y: Intracranial complications of ethmoiditis evidenced by magnetic resonance imaging. Ann Otol Rhinol Laryngol 2001;110:592-595.

63 Abuhammour WM, Abdel-Haq NM, Asmar BI, Dajani AS: Moraxella catarrhalis bacteremia: A 10-year experience. South Med J 1999; 92:1071-1074.

64 Lehnerdt G, Weber J, Dost P: Unilateral opacification of the paranasal sinuses in CT or MRI: An indication of an uncommon histological finding. Laryngorhinootologie 2001;80: 141-145. (Article in German.)

-65 Kuhn UM, Mann WJ, Amedee RG: Endonasal approach for nasal and paranasal sinus tumor removal. ORL J Otorhinolaryngol Relat Spec 2001;63:366-371.

66 Messerklinger W: Endoscopy of the nose. Monatsschr Ohrenheilkd Laryngorhinol 1970;104: 451-456.

67 Messerklinger W: Technics and possibilities of nasal endoscopy. HNO 1972;20:133-135.

68 Wigand ME: Transnasal, endoscopical sinus surgery for chronic sinusitis. I. A biomechanical concept of the endonasal mucosa surgery. HNO 1981;29:215-221.

69 Kennedy DW: Functional endoscopic sinus surgery: Technique. Arch Otolaryngol 1985; 111:643-649.

70 Stammberger $\mathrm{H}$ : Endoscopic endonasal surgery - Concepts in treatment of recurring rhinosinusitis. II. Surgical technique. Otolaryngol Head Neck Surg 1986;94:147-156.

71 Stammberger H, Posawetz W: Functional endoscopic sinus surgery. Concept, indications and results of the Messerklinger technique. Eur Arch Otorhinolaryngol 1990;247:63-76.

72 Kennedy DW: Prognostic factors, outcomes and staging in ethmoid sinus surgery. Laryngoscope 1992;102(suppl 57):1-18.

73 Lund VJ, Mackay IS: Staging in rhinosinusitus. Rhinology 1993;31:183-184.

74 Lund VJ, Kennedy DW: Quantification for staging sinusitis. The Staging and Therapy Group. Ann Otol Rhinol Laryngol Suppl 1995; 167:17-21

75 Lund VJ, Kennedy DW: Staging for rhinosinusitis. Otolaryngol Head Neck Surg 1997;117: $35-40$.

76 Lund VJ: Objective assessment of nasal obstruction. Otolaryngol Clin North Am 1989;22: 279-290.

77 Lund VJ, Holmstrom M, Scadding GK: Functional endoscopic sinus surgery in the management of chronic rhinosinusitis. An objective assessment. J Laryngol Otol 1991;105:832835.

78 Lund VJ, Scadding GK: Objective assessment of endoscopic sinus surgery in the management of chronic rhinosinusitis: An update. J Laryngol Otol 1994; 108:749-753.

79 Stammberger H: Endoscopic endonasal surgery - Concepts in treatment of recurring rhinosinusitis. I. Anatomic and pathophysiologic considerations. Otolaryngol Head Neck Surg 1986;94:143-147.
80 Stammberger $\mathrm{H}$ : The evolution of functional endoscopic sinus surgery. Ear Nose Throat $\mathrm{J}$ 1994;73:451-455.

81 Stammberger H, Zinreich SJ, Kopp W, Kennedy DW, Johns ME, Rosenbaum AE: Surgical treatment of chronic recurrent sinusitis - The Caldwell-Luc versus a functional endoscopic technique. HNO 1987;35(3):93-105.

82 McCaffrey TV: Functional endoscopic sinus surgery: An overview. Mayo Clin Proc 1993; 68:571-577.

83 Smith LF, Brindley PC: Indications, evaluation, complications, and results of functional endoscopic sinus surgery in 200 patients. Otolaryngol Head Neck Surg 1993;108:688-696.

84 Kuehnemund M, Lopatin A, Amedee RG, Mann WJ: Endonasal sinus surgery: Extended versus limited approach. Am J Rhinol 2002; 16 : 187-192.

85 Dixon HS: Microscopic sinus surgery, transnasal ethmoidectomy and sphenoidectomy. Laryngoscope 1983;93:440-444.

86 Amedee RG, Mann WJ, Gilsbach JM: Microscopic endonasal surgery of the paranasal sinuses and the parasellar region. Arch Otolaryngol Head Neck Surg 1989;115:1103-1106.

87 Stammberger H: Endoscopic paranasal sinus surgery: Microscope versus endoscope? HNO 1996;44:287.

88 Tasman AJ, Wallner F, Kolling GH, Stammberger $\mathrm{H}$ : Is monocular perception of depth through the rigid endoscope a disadvantage compared to binocular vision through the operating microscope in paranasal sinus surgery? Am J Rhinol 1998;12:87-91.

89 Klimek L, Amedee RG, Krause-Bonte M, Mann WJ: Endoscope-microscope combination for endonasal sinus surgery. Otolaryngol Head Neck Surg 1998;119:533-535.

90 Christmas DA Jr, Krouse JH: Powered instrumentation in functional endoscopic sinus surgery. I. Surgical technique. Ear Nose Throat J 1996;75:33-36, 39-40.

91 Krouse JH, Christmas DA Jr: Powered instrumentation in functional endoscopic sinus surgery. II. A comparative study. Ear Nose Throat J 1996;75:42-44.

92 Nguyen QA, Leopold DA: Current concepts in the surgical management of chronic frontal sinusitis. Otolaryngol Clin North Am 1997;30: 355-370.

93 Krouse JH, Christmas DA Jr: Powered nasal polypectomy in the office setting. Ear Nose Throat J 1996;75:608-610.

94 Setliff RC 3rd: The hummer: A remedy for apprehension in functional endoscopic sinus surgery. Otolaryngol Clin North Am 1996;29: 95-104.

95 Lopatin AS, Piskunov GZ: The Hummer Microdebrider - New technology in functional endonasal rhinosurgery. Vestn Otorinolaringol 1996;6:54-57.

96 Hamels K, Morre TD, Clement PA: The hummer, shaver or microdebrider. Acta Otorhinolaryngol Belg 1997;51:89-91. 
$\$ 97$ Kuhnel T, Hosemann W, Rothammer R: Evaluation of powered instrumentation in out-patient revisional sinus surgery. Rhinology 2001;39:215-219.

98 Krouse HJ, Parker CM, Purcell R, Krouse $\mathrm{JH}$, Christmas DA: Powered functional endoscopic sinus surgery. AORN J 1997;66:405, 408-411, 413-414.

$\$ 99$ Ferguson BJ, DiBiase PA, D’Amico F: Quantitative analysis of microdebriders used in endoscopic sinus surgery. Am J Otolaryngol 1999;20:294-297.

100 Selivanova O, Kuehnemund M, Mann WJ, Amedee RG: Comparison of conventional instruments and mechanical debriders for surgery of patients with chronic rhinosinusitis. Am J Rhinol 2003; in press.

101 Schlondorff G, Mosges R, Meyer-Ebrecht D, Krybus W, Adams L: CAS (computer assisted surgery). A new procedure in head and neck surgery. HNO 1989;37:187-190.

102 Fried MP, Kleefield J, Gopal H, Reardon E, Ho BT, Kuhn FA: Image-guided endoscopic surgery: Results of accuracy and performance in a multicenter clinical study using an electromagnetic tracking system. Laryngoscope 1997;107:594-601.

103 Anon JB: Computer-aided endoscopic sinus surgery. Laryngoscope 1998;108:949-961.

104 Klimek L, Ecke U, Lubben B, Witte J, Mann $\mathrm{W}$ : A passive marker-based optical system for computer-aided surgery in otorhinolaryngology: Development and first clinical experiences. Laryngoscope 1999;109:1509-1515.

$>105$ Olson G, Citardi MJ: Image-guided functional endoscopic sinus surgery. Otolaryngol Head Neck Surg 2000;123:188-194.

106 Klimek L, Mosges R, Schlondorff G, Mann W: Development of computer-aided surgery for otorhinolaryngology. Comput Aided Surg 1998:3:194-201.

- 107 Ecke U, Khan M, Maurer J, Boor S, Mann $\mathrm{WJ}$ : Intraoperative navigation in surgery of paranasal sinus and anterior skull base. HNO 2002;50:928-934.

108 Khan M, Ecke U, Mann WJ: The application of an optical navigation system in endonasal sinus surgery. HNO 2003;51:209-215.
109 Caversaccio M, Bachler R, Ladrach K, Schroth G, Nolte LP, Hausler R: Frameless computer-aided surgery system for revision endoscopic sinus surgery. Otolaryngol Head Neck Surg 2000;122:808-813.

110 Luxenberger W, Kole W, Stammberger H, Reittner P: Computer assisted localization in endoscopic sinus surgery - State of the art? The Insta Trak system. Laryngorhinootologie 1999; 78:318-325.

111 Moses RL, Cornetta A, Atkins JP Jr, Roth M, Rosen MR, Keane WM: Revision endoscopic sinus surgery: The Thomas Jefferson University experience. Ear Nose Throat J 1998;77: 190, 193-195, 199-202.

112 Sharp HR, Crutchfield L, Rowe-Jones JM, Mitchell DB: Major complications and consent prior to endoscopic sinus surgery. Clin Otolaryngol 2001;26:33-38.

113 Freedman HM, Kern EB: Complications of intranasal ethmoidectomy: A review of 1,000 consecutive operations. Laryngoscope 1979; 89:421-434.

114 Lund VJ, Wright A, Yiotakis J: Complications and medicolegal aspects of endoscopic sinus surgery. J R Soc Med 1997;90:422428.

115 Dessi P, Castro F, Triglia JM, Zanaret M, Cannoni M: Major complications of sinus surgery: A review of 1192 procedures. J Laryngol Otol 1994;108:212-215.

116 Mackay IS: Endoscopic sinus surgery - Complications and how to avoid them. Rhinol Suppl 1992;14:151-155.

117 Ikeda K, Hirano K, Oshima T, Shimomura A, Suzuki H, Sunose H, Kondo Y, Takasaka T: Comparison of complications between endoscopic sinus surgery and Caldwell-Luc operation. Tohoku J Exp Med 1996;180:27-31.

118 Weber R, Keerl R, Hosemann W, Schauss F, Leuwer R, Draf W: Complications with permanent damage in endonasal paranasal sinus operations - more frequent in experienced surgeons? Laryngorhinootologie 1998;77: 398-401.

119 Keerl R, Stankiewicz J, Weber R, Hosemann W, Draf W: Surgical experience and complications during endonasal sinus surgery. Laryngoscope 1999;109:546-550.
120 Wu C, Sun S, Yu B, Song W, Zhang Z: Study on the factors in the complications of endonasal sinus surgery. Lin Chuang Er Bi Yan Hou Ke Za Zhi 2002;16:395-396.

121 Gosepath J, Amedee RG, Romantschuck S, Mann WJ: Breathe right nasal strips and the respiratory disturbance index in sleep related breathing disorders. Am J Rhinol 1999;13: 385-389.

122 Abdel-Hak B, Gunkel A, Kanonier G, Schrott-Fischer A, Ulmer H, Thumfart W: Ciliary beat frequency, olfaction and endoscopic sinus surgery. ORL J Otorhinolaryngol Relat Spec 1998;60:202-205.

123 Klimek L, Moll B, Amedee RG, Mann WJ: Olfactory function after microscopic endonasal surgery in patients with nasal polyps. Am J Rhinol 1997;11:251-255.

124 Delank KW, Stoll W: Olfactory function after functional endoscopic sinus surgery for chronic sinusitis. Rhinology 1998;36:15-19.

125 Rowe-Jones JM, Mackay IS: A prospective study of olfaction following endoscopic sinus surgery with adjuvant medical treatment. Clin Otolaryngol 1997;22:377-381

126 Dunlop G, Scadding GK, Lund VJ: The effect of endoscopic sinus surgery on asthma: Management of patients with chronic rhinosinusitis, nasal polyposis, and asthma. Am J Rhinol 1999; 13:261-265.

127 Senior BA, Kennedy DW, Tanabodee J, Kroger H, Hassab M, Lanza DC: Long-term impact of functional endoscopic sinus surgery on asthma. Otolaryngol Head Neck Surg 1999;121:66-68.

128 Hosemann W, Schwab N, Praetner L, Breme K, Beule A, Kaftan H: Extended outcome assessment in endonasal sinus surgery. Laryngorhinootologie 2003;82:341-346.

129 Senior BA, Kennedy DW, Tanabodee J, Kroger H, Hassab M, Lanza D: Long-term results of functional endoscopic sinus surgery. Laryngoscope 1998;108:151-157.

130 Damm M, Quante G, Jungehuelsing M, Stennert $\mathrm{E}$ : Impact of functional endoscopic sinus surgery on symptoms and quality of life in chronic rhinosinusitis. Laryngoscope 2002; 112:310-315. 